\title{
Revista Brasileira de Enfermagem REBEn A convivência da família com o portador de
Síndrome de Down à luz da Teoria Humanística
}

The family living with Down Syndrome

patients in the perspective of Humanistic Theory

La vivencia de la família de lo portador de

Síndrome de Down según la Teoría Humanistica

\section{Acaciane Frota Ramos}

Enfermeira graduada pela Universidade Estadual Vale do Acaraú - UVA.

Joselany Afio Caetano

Enfermeira. Doutora em Enfermagem pela Universidade Federal do Ceará/UFC. Professora do Curso de Enfermagem da Universidade de Fortaleza/UNIFOR. joselany@unifor.br

\section{Enedina Soares}

Doutora em Enfermagem. Professora permanente do Programa de Pós-Graduação da UNIRIO.

\section{Karla Maria Carneiro Rolim}

Enfermeira da Maternidade Escola Assis Chateaubriand/MEAC/UFC. Mestre em Enfermagem. Doutoranda em Enfermagem pela Universidade Federal do Ceará/UFC.

Professora do Curso de Enfermagem da Universidade de Fortaleza/UNIFOR. karlarolim@unifor.br
Submissão: 20/07/2005

Aprovação: 05/01/2006

\section{RESUMO}

Este estudo teve como objetivo socializar o processo de convivência da família de portadores da síndrome de Down com base na teoria humanística de Paterson e Zderad. Foi realizado na Associação de Pais e Amigos dos Excepcionais - APAE, localizada no município de Sobral - CE. Para coleta de dados utilizamos dinâmicas de grupo, observação participante e entrevista norteadora. Observamos, no estudo, que a convivência familiar ocorre de forma natural, ou seja, os pais desempenham seu papel, buscando o bem-estar e o estar melhor de seus filhos.Verificamos que os esforços dos pais que tentam diminuir as diferenças entre os portadores da síndrome de Down e os normais, como também diminuir e até combater o preconceito imposto pela sociedade foram bastante enfocados. Apreendemos que a tentativa dos pais em diminuir as diferenças pode minimizar os preconceitos impostos pela sociedade teve bastante relevância..

Descritores:Síndrome de Down; Relações familiares; Teoria de Enfermagem.

\section{ABSTRACT}

The objective of this study was to socialize the process of coexistence of the family of the bearers of syndrome of Down based in the Humanistic Theory of Paterson and Zderad. The study was realized with a research of descriptive exploratory character, with a qualitative approach and participant observation. It was accomplished in APAE / Sobral-CE, with the use of group dynamics and a guided interview for collection of data. The results showed us that the parents don't have difference between a normal son and a special one; the treatment is the same, with a lot of love, affection, understanding and respect, however a lot of times they find some difficulties in taking care, as the communication and the feeding. We also observed that the family is very important, necessary, so that the coexistence with the bearer becomes more and more natural in spite of a society that, a lot of times, still has prejudiced.

Descriptors: Down Syndrome; Family relations; Nursing theory.

\section{RESUMEN}

Ese estudio tuvo como objetivo socializar el proceso de convivencia de la familia de portadores del síndrome de Down con base en la teoría humanística de Paterson y Zderad. Fue realizado en la Asociación de Padres y Amigos de los Excepcionales - APAE, localizada en el municipio de Sobral-Ce. Para colecta de datos utilizamos dinámicas de grupo, observación participante y entrevista orientada. Observamos, en el estudio, que la convivencia familiar ocurre de forma natural, es decir, los padres desempeñan su función, recogiendo el bienestar y el estar mejor de sus hijos. Verificamos que los esfuerzos de los padres que intentan disminuir las diferencias entre los portadores de síndrome de Down y los normales, como también disminuir y hasta combatir el prejuicio impuesto por la sociedad fueron bastante enfocados. Aprehendemos que la tentativa de los padres en disminuir las diferencias puede minimizar los prejuicios impuestos por la sociedad tuvo bastante relevancia.

Descriptores: Sindrome de Down; Relaciones familiares; Teoría de Enfermeria.

Ramos AF, Caetano JA, Soares E, Rolim KMC. A convivência da família com o portador de Síndrome de Down à luz da Teoria Humanística. Rev Bras Enferm 2006 maio-jun; 59(3): 262-8.

\section{INTRODUÇÃO}

A síndrome de Down é o resultado de um acidente genético causado pela trissomia do cromossomo 21 , que ocorre em uma determinada fase do desenvolvimento intra-uterino. Um indivíduo com esta anomalia possui 47 cromossomos, ao invés dos 46 encontrados em indivíduos normais ${ }^{(1)}$. Esta síndrome possui as seguintes características: braquicefalia, fissuras palpebrais oblíquas, pregas no epicanto, manchas de Brushfild, ponte do nariz achatada, protrusão da língua, orelhas pequenas e de implantação baixa, clinodactilia, prega simiesca, defeitos cardíacos congênitos, hipotonia, retardo mental e do crescimento, pele seca e escamosa ${ }^{(2)}$. 
O diagnóstico pode ser feito em bases puramente clínicas. A impressão geral especialmente da fácies é muito importante. Casos duvidosos são mais comuns na primeira infância, especialmente em recém-nascidos cujos sinais clínicos podem ser menos claros. É uma das anomalias cromossômicas mais comuns, com uma incidência populacional de aproximadamente um em cada 600 nascimentos vivos $^{(2,3)}$.

Estima-se que 3\% da população mundial sejam portadoras da síndrome de Down, com maior prevalência em indivíduos brancos, sendo rara em negros ${ }^{(4)}$. A incidência aumenta com a idade materna avançada (o risco para idade materna de 25 anos é de um em 1350; aos 35 anos, de um em 384; aos 45 anos, de um em 28)(2).

Pesquisas sobre a aceitação dos portadores da síndrome de Down pela família em uma determinada população são imprescindiveis para o planejamento de programas de informações e preparo para receber uma criança com síndrome de Down ${ }^{(5)}$. A família busca adaptar-se à nova realidade e reorganizar-se para enfrentar a experiência de viver e conviver com a síndrome, ou seja, reconstruir sua identidade como grupo familiar. A família é, também, o universo fornecedor de condições para que o processo de construção equilibrado e harmonioso proporcione à criança meios de se individualizar e florescer como ser único no mundo(6)

$\mathrm{O}$ interesse pelo tema surgiu após o desenvolvimento de projeto de pesquisa, no segundo período do Curso de Graduação em Enfermagem, na disciplina Sociologia da Saúde, que teve sua prática desenvolvida na APAE (Associação de Pais e Amigos dos Excepcionais), no município de Sobral - CE. Ao manter uma interação com os pais, observamos que, como pessoas sensíveis e carinhosas, eles se preocupavam muito com os filhos e com os profissionais envolvidos no cuidado. Percebemos, então, a necessidade de promover ações na atenção primária à saúde, devendo incluir atividades sistemáticas, buscando a detecção precoce de problemas e mecanismos que fossem capazes de resolvê-los, e, assim, promover melhor qualidade de vida. Ações estas que poderiam ser executadas pela equipe de enfermagem, apesar de estes profissionais não fazerem parte da equipe multiprofissional da APAE. Portanto, seria de grande relevância para os portadores da síndrome, essa elaboração dialógica e participativa de novos conhecimentos entre os participantes, viabilizando o aprendizado, novos saberes e práticas em saúde.

Este estudo foi embasado na Teoria Humanística de Paterson e Zderad $^{(7)}$, que fornece um método para administrar as complexidades que envolvem o ser no mundo e também uma ponte metodológica entre a teoria e a prática, servindo como um amplo guia para o diálogo da enfermagem em diversos cenários da profissão(8).

A Teoria da Enfermagem Humanística surgiu, na década de 1970, a partir de experiências das enfermeiras Josephine Paterson e Loretta Zderad no campo da docência e da assistência de Enfermagem e por meio de cursos sobre enfermagem humanística que ministraram para enfermeiras do hospital onde atuavam nos Estados Unidos. $O$ conteúdo da teoria revela a influência do existencialismo, do humanismo e da fenomenologia, sendo citados escritores como Husserl, Buber, Marcel, Jung, Nietzsche, entre outros ${ }^{(7)}$.

As teóricas propõem que a enfermagem - diálogo vivido - seja desenvolvida como uma experiência existencial, em que a enfermeira, após vivenciá-la, reflete sobre ela e descreve, fenomenologicamente, os chamados e as respostas que surgiram na relação, bem como 0 conhecimento humano do eu e do outro, isto é, reconhecer o outro em sua singularidade, como alguém que luta e se esforça para sobreviver, o vir a ser, confirmar sua existência e entendê-la. Nesse diálogo, estão envolvidos o encontro, a relação, a presença, o chamado e a resposta ${ }^{(9)}$.

0 pensar e 0 agir voltados para a assistência, não a um paciente, mas a um ser humano, deve levar em consideração a sua história de vida, ser prioridade em todas as áreas, principalmente na saúde, pois a partir de uma falha nesse processo podemos desestruturar ainda mais 0 indivíduo que naquele momento já precisa de cuidados ${ }^{(10)}$.

Portanto, a assistência de enfermagem deve ser mais atuante ao portador da síndrome de Down, pois se mostra um promissor espaço profissional a ser explorado pela enfermagem. Neste contexto, o objetivo deste estudo é socializar o processo de convivência da família de portadores da síndrome de Down com base na Teoria Humanística de Paterson e Zderad, caracterizando-se a assistência de enfermagem pela promoção do bem-estar e do estar melhor do paciente, por meio de um cuidado holístico e empático no qual a assistência ao indivíduo e sua família não pode ser negligenciada.

Um atendimento humanizado requer mudanças de cultura, trazendo um paradigma no qual a pessoa seja recebida como única dotada de sua história pessoal, com seus valores e suas crenças. A humanização entre a equipe, o portador de síndrome de Down e a família objetiva, como condição essencial, a vontade de encontrar e de ser encontrado. Esse encontro pressupõe escuta, olhar aberto e amoroso. 0 cuidador deve desenvolver uma capacidade de se conhecer e saber reconhecer seus sentimentos, como amor e empatia, entre outros. Essa capacidade diminui as possibilidades de conflito, pois abre caminhos para a comunicação com o outro.

O cuidado integral à criança portadora de deficiência e a promoção da sua qualidade de vida promovem a reabilitação da criança na capacidade funcional e no desempenho humano, a proteção à saúde para que ela possa desempenhar o seu papel em todas as esferas da vida social(11). 0 cuidado humano e ético envolve alguns ingredientes especiais da enfermeira, entre os quais, o conhecimento, a humildade, a paciência, a honestidade, a esperança, que, juntos, estabelecem uma parceria com o portador de síndrome de Down, um sentimento de estar com, denotando a verdadeira presença, a experiência e o compromisso profissional.

\section{TRAÇADO TEÓRICO METODOLÓGICO}

0 presente estudo, de caráter exploratório descritivo, tem como principal finalidade desenvolver, esclarecer, modificar conceitos e idéias, tendo em vista a formulação de problemas mais precisos ou hipóteses para estudos posteriores ${ }^{(12)}$. A pesquisa descritiva é um levantamento das características conhecidas ou componentes do fato, fenômeno ou problema $^{(13)}$

O estudo foi realizado na Associação de Pais e Amigos dos Excepcionais (APAE), situada no município de Sobral - CE. A APAE é um estabelecimento de ensino para pessoas especiais, que presta serviços de reabilitação e habilitação. Possui uma equipe multiprofissional e seus recursos financeiros são provenientes do Sistema Único de Saúde/SUS, doações sociais, contribuintes e convênio com o Estado e o Município.

A clientela assistida na Instituição é acompanhada por uma equipe composta por dentista, fonoaudiólogo, psicólogo, terapeuta ocupacional, assistente social e educador físico.

A população deste estudo constou de 16 pais com filhos portadores da síndrome de Down e matriculados na APAE de Sobral/CE. Desta população foram selecionados sete pais residentes na cidade de Sobral, que demonstraram interesse em participar da oficina de grupo, que aconteceu, semanalmente, durante o mês de dezembro de 2004 .

Utilizamos, como metodologia para a compreensão do fenômeno das situações em que vive a enfermeira, a teoria humanística ${ }^{(7)}$ constituída das seguintes fases:

Preparação para vir a conhecer - fase em que a enfermeira busca conhecer a si própria, por meio de leitura reflexiva de obras que falam sobre a natureza do homem e suas diferentes formas de perceber $e$ relacionar-se com o mundo e de tornar seus pensamentos e atitudes mais humanas. A partir dessas reflexões, são feitas comparações com 
a prática da Enfermagem ${ }^{(7)}$.

Conhecendo o outro intuitivamente - fase na qual a intuição supõe a relação Eu-Tu de Buber, para que a enfermeira consiga captar, de modo intuitivo, o fenômeno de uma situação de enfermagem, sem quaisquer noções preconceituosas, evitando, por isso, expectativas, rótulos e julgamentos $^{(9)}$.

Conhecendo o outro cientificamente - fase em que a enfermeira, após conhecer 0 outro intuitivamente, conceitua a experiência e a expressa segundo o seu potencial humano. É o momento de refletir, analisar, classificar, comparar, contrastar, relacionar, interpretar, denominar e categorizar. É a relação Eu-Tu e Eu-Isso de Buber, ocorrendo simultaneamente, e não apenas na seqüência por ele expressada ${ }^{(7)}$.

Sintese complementar do conhecimento dos outros - quarta fase da Enfermagem Fenomenológica, que representa o momento de a enfermeira comparar e sintetizar as múltiplas realidades conhecidas, para, então, chegar a uma visão ampliada. A enfermeira estabelece relações entre essas realidades e as interpreta, seleciona e classifica. Nessa fase, ela usa não apenas a experiência pessoal, mas também os ricos fundamentos teóricos de educação e de prática ${ }^{(9)}$.

Sucessão do nós para o único paradoxal - fase que evolui a partir do processo descritivo de um fenômeno vivido. Nesta fase, através de reflexões sobre as relações entre as múltiplas visões, a enfermeira faz uma revisão compreensiva e expande sua própria visão. Na busca pela comunhão de idéias diferentes, a enfermeira chega a uma visão que vai além das multiplicidades e contradições, tornando-se importante para a maioria ou para todos ${ }^{(7)}$.

Para obtermos as informações necessárias ao desenvolvimento do estudo, utilizamos também como estratégia o grupo focal como parte das técnicas de coleta de dados, oficinas e entrevista com uma questão norteadora. As dinâmicas de grupo foram os primeiros passos para a pré-reflexão, revisão de literatura e esclarecimento da problemática do estudo, constituindo a primeira fase da Teoria Humanística "preparação para o vir a conhecer".

0 processo de conhecer intuitivamente o outro aconteceu quando vivenciamos a relação Eu-Tu com a família, mediante as seguintes dinâmicas: "jornada nas estrelas"; "classificados obstétricos"; "com que cara está chegando"; "desejo ao próximo" e "cores dos sentimentos".

$\mathrm{Na}$ condição de conhecer o outro e de "estar com" e "fazer com", houve maior envolvimento com a família dos pesquisados, com o intuito de contrastar experiências e visualizar o encontro que refletiu o diálogo vivo entre os seres humanos. Neste momento, usamos as dinâmicas "construção da árvore", "apresentando seu filho", "o boneco" e a "dinâmica da garrafa".

Com o desenvolver do processo relacional houve maior participação das famílias e liberdade. Assim, as etapas "preparação para o vir a conhecer" e "conhecendo o outro intuitivamente" foram introdutórias para o "conhecer o outro cientificamente", momento final, em que foi apresentada a questão norteadora ao entrevistado: "Como é o conviver com uma pessoa portadora de síndrome de Down"? Este momento caracterizou o final da coleta de dados.

Utilizamos o método da observação participante, que é um processo no qual o observador está face a face com o observado e, efetivamente, participa da situação, até mesmo intervindo, mudando, propondo(13). Como participante desse processo, acompanhamos cada dinâmica. Com base neste método, as observações foram registradas em diário de campo, no mesmo dia do encontro, de forma detalhada, por meio de anotações de campo e memorizações, primando pela fidedignidade das falas e fatos.

As falas foram transcritas e, em seguida, digitadas e lidas, quando então se buscaram os significados, relacionando-os ao tema, conforme o pensamento humanístico ${ }^{(7)}$. Com a realização das entrevistas, houve maior aprofundamento dos dados e, após suas transcrições, nos foi possivel verificar dos pais as opiniões sobre a importância do conviver em família.

A projeto foi submetido à apreciação do Comitê de Ética e Pesquisa da Universidade Estadual Vale do Acaraú e seguiu a Resolução № 196/ 96 do Conselho Nacional de Saúde, que estabelece critérios para pesquisas em seres humanos e enfatiza a necessidade do consentimento informado e a manutenção do sigilo e anonimato dos participantes $^{(14)}$.

Na fase de pré-análise, de posse do conteúdo das oficinas e das entrevistas, realizamos leitura flutuante para conhecermos e analisarmos os fenômenos encontrados. Para melhor compreensão dos dados obtidos, utilizamos a técnica da análise de conteúdo, que é definida como conjunto de técnicas de análise de comunicação, visando a obter, por procedimentos sistemáticos e objetivos de descrição do conteúdo das mensagens, indicadores que permitissem a inferência de conhecimentos relativos às condições de produção/recepção destas mensagens ${ }^{(15)}$.

A análise foi realizada à luz dos pressupostos básicos da Teoria Humanística, com enfoque no diálogo que contempla o encontro, o relacionamento, a presença, o chamado e a resposta, favorecendo a família, o bem-estar e o estar melhor ${ }^{(7)}$.

Para identificação dos pais participantes, adotamos nomes de flores como cognomes, pois, ao fazer analogia com a pessoa humana, flores são símbolos da natureza, da vida, de pureza, de paz, de riqueza, de sucesso, de energia, de cura, de amor, de qualidade de vida.

\section{APRESENTAÇÃO E ANÁLISE DOS DADOS: O CAMINHAR DA CONVIVÊNCIA}

A análise dos resultados deste estudo foi realizada à luz da Teoria Humanística de Paterson e Zderad. Para vivenciá-la, foi necessário relembrar a linguagem dos sentidos, enfocando a visão, a audição e a percepção sensivel do outro. Os pais foram convidados a participarem aos encontros independentemente da idade de seus filhos. Os encontros foram realizados pela manhã na quadra de esportes da APAE.

Compareceram ao primeiro encontro seis pessoas. Inicialmente, demos boas vindas, sentamos em círculo, nos apresentamos, dissemos o objetivo da pesquisa e, também, firmamos os demais encontros.

A nossa apresentação foi de fundamental importância, pois pudemos esclarecer quem somos e como pretendíamos atuar com o grupo, tornando-nos membro do mesmo. Percebemos que isso favorecia a interação com eles. O relacionamento humano é um instrumento essencial para a assistência de enfermagem, em que empatia, aptidão de compartilhar sentimentos e estar perto de outra pessoa são elementos para um relacionamento terapêutico ${ }^{(16)}$. Assim, tornou-se primordial a busca do conhecimento, a preparação para o vir a conhecer, fazendo-nos abertos às experiências do mundo.

No primeiro encontro, utilizamos a dinâmica "jornada nas estrelas", com a sugestão para o grupo andar no espaço ambiental disponível e observar objetos. Em seguida, deslocar-se ao centro do ambiente e escolher uma estrela entre as previamente colocadas pelo coordenador, confeccionadas com papel laminado, com cores variadas. Cada um escreveu no centro da estrela como gosta de ser chamado e uma coisa de que gosta e não gosta, para depois fazer sua apresentação. A estrela deveria posteriormente ser colocada em algum lugar do ambiente pedagógico, representando os espaços relacionados ao simbolismo em face da relação com o mundo, objetivando facilitar a apresentação do grupo.

Sou o Girassol, gosto de conversar e sou a Chuva de Prata, gosto de cozinhar e não gosto de lavar roupa.

Além de nos apresentar, enfatizamos: 
Eu sou o Lírio, gosto de trabalhar e não gosto de que falem mal do meu filho.

Eu sou Margarida, gosto de conhecer coisas novas e não gosto de bagunça.

Eu sou Dália, gosto de cozinhar e não gosto de mentira.

Eu sou Tulipa, gosto de ir à missa e não gosto de falsidade.

Eu sou Gardênia, gosto de rezar e não gosto de injustiça.

Eu não gosto de gente mentirosa.

Relatei novamente a idéia de participar de um grupo de pais que se reuniriam para contar suas vivências no conviver com o portador de síndrome de Down e, também, esclarecer dúvidas e dificuldades que pudessem surgir. Abrimos espaços para perguntas, mas os participantes comentaram que haviam entendido e aceitaram a idéia.

Nesta fase do estudo cada um apresentou-se, contando algo sobre sua vida e questões delicadas que podemos exemplificar na fala de Lírio: "[...] não gosto de que falem mal do meu filho", demonstrando, assim, carinho, respeito e proteção.

Percebemos que essa dinâmica auxiliou na interação e na empatia, pois seu aspecto lúdico favoreceu a ambientação do grupo. As tecnologias educativas em nossa prática assistencial são atividades lúdicas que criam oportunidades de convívio e relações enriquecedoras para os participantes. Sua aplicação é planejada e executada de acordo com a necessidade da situação vivenciada, tendo objetivos claros que levam a uma meta estabelecida ${ }^{(17)}$.

Logo em seguida, conhecemos o antecedente obstétrico do grupo, através dos "classificados obstétricos", com o objetivo de conhecer o antecedente obstétrico das mães. Primeiramente, cada participante confeccionou um diário que continha dados sobre sua identificação, antecedentes obstétricos e história da gravidez; em seguida procedemos à exposição e análise, na tentativa de explorar o discurso e o conhecimento do grupo.

A mãe dele hoje tem 38 anos, teve 6 gestações e 6 partos, realizou pré-natal.

Teve nosso filho no Dr. Estevam, foi parto normal. Ele passou 5 dias na incubadora. E nós ficamos sabendo que ele não era normal assim que ele nasceu. Quando o nosso filho nasceu, a mãe dele tinha 34 anos... mamou até 3 meses e eu tenho um sobrinho que tem sindrome de Down (Lírio).

Ela perdeu sangue e líquido no começo (Lírio).

Eu tive minha filha com 42 anos, hoje tenho 72 anos, mas fiz prénatal em Fortaleza e tive-a lá. Soube da notícia assim que ela nasceu: o médico me disse; ela mamou até 2 anos (Girassol).

Eu tive meu filho com 18 anos, fiz pré-natal, pari na Santa Casa e soube que ele tinha Down após 4 meses. Amamentei até 5 meses (Margarida).

Eu o tive com 40 anos. Hoje ele tem 12 anos. Fiquei grávida 5 vezes, tive um aborto e tenho 4 filhos; não fiz pré-natal, nem exames; meu parto foi normal;... eu não amamentei meu filho, naquele tempo ninguém tinha informação. Hoje já tem... (Tulipa).

Cada participante compartilhou com o grupo seu antecedente obstétrico, história da gravidez, parto, puerpério, ambiente hospitalar, momento da notícia sobre seu filho e amamentação.

Diante destas falas constatamos que naquela população a incidência da síndrome de Down é maior nas mães com idade superior a 35 anos ou mais. Ocasionalmente, a criança com síndrome de Down é o primeiro filho de uma mãe jovem ${ }^{(18)}$. Verificamos, também, que elas amamentaram seus filhos, com exceção de Tulipa, que, por falta de orientação, deixou de oferecer um alimento rico em nutrientes e muito importante para a saúde, crescimento e desenvolvimento.

Amamentar bebês com síndrome de Down é o primeiro e principal passo para que se estimule a musculatura bucal e facial. 0 aleitamento materno é o melhor que pode existir para estes bebês, tanto como nutrição, como trabalho muscular. Além de ajudar a melhorar o tônus muscular dos lábios, boca e língua, é muito importante para 0 desenvolvimento dos dentes e da linguagem ${ }^{(19)}$.

As famílias, ao receberem a notícia de que o filho é portador de síndrome de Down, necessitam de segurança, apoio, confiança e dignidade, fazendo com que não fujam da realidade, mas enfrentem-na e construam algo. Para isso, as enfermeiras devem estar em sintonia com a paz e o bem-estar, pois é o amor a justa medida, a ternura, a cordialidade, a convivência e a compaixão que garantem a humanidade das pessoas ${ }^{(20)}$.

Depois desse momento, procuramos deixar as participantes conversando. Em seguida, fizemos a "construção da árvore", para identificar as facilidades e as dificuldades no ato de cuidar do seu filho. A árvore foi construída com folhas verdes e amarelas, onde as folhas verdes representaram as facilidades no cuidado e as folhas amarelas, as dificuldades do cuidado com o portador de síndrome de Down. Na ocasião, cada participante colocou suas folhas fixadas na parede, próxima ao caule, dando a idéia de uma árvore.

Eu gosto de cuidar dele, porque ele é uma criança muito ativa e carinhosa, mas a maior dificuldade é controlar sua alimentação; ele não gosta de brincar com os outros e ele não fala (Gardênia).

Ela já não me dá muito trabalho, até que ela é obediente, mas nós temos uma dificuldade, ela é muito enraivada quando não fazemos o que ela quer (Chuva de Prata).

É fácil cuidar da alimentação, da higiene e da educação. Minha maior dificuldade é a comunicação com ele, pois ele não fala bem, ficando difícil de entender o que ele realmente sente (Margarida).

As facilidades que encontro no cuidar dele é na sua alimentação, pois ele não dá trabalho para comer, na higiene. Ele é brincalhão, alegre e obediente. 0 que mais dificulta é a comunicação Estou muito preocupado com a questão da fala (Lírio).

Os portadores da síndrome de Down têm uma tendência à obesidade. Percebemos, então, a necessidade de um controle alimentar, pois a obesidade acarreta uma série de problemas para a saúde.

Vimos também que, na maioria dos depoimentos, a comunicação representa uma preocupação para os pais. A criança com síndrome de Down apresenta um atraso na aquisição e desenvolvimento da linguagem, se comparada a outra criança. Este atraso ocorre nas características físicas ou ambientais que influenciam negativamente 0 processo de desenvolvimento, tais como: problemas de acuidade e discriminação auditiva, alteração do alinhamento dos dentes, língua grande (macroglossia) ou cavidade oral pequena, dentre outros. De maneira geral, a criança, o jovem, ou o adulto com síndrome de Down possuem dificuldades variadas no desenvolvimento da linguagem; por isso, é importante o quanto antes criar um ambiente propício para 
favorecer a evolução da linguagem, porque, agindo assim, melhor será o seu futuro ${ }^{(21)}$.

Ao final deste encontro, despedimo-nos, agradecendo a presença, a participação e convidamos para o próximo momento, enfatizando que a data e local seriam comunicados para os seus filhos. Cada encontro foi preparado de forma particularizada, levando-se em consideração as situações vivenciadas, bem como os dados coletados nos encontros anteriores. $O$ resultado desses encontros tornou-se um somatório, tendo sempre em vista que cada momento teve sua particularidade.

Ao segundo encontro compareceram cinco pais, sendo que dois já tinham participado do primeiro encontro e os demais estavam participando pela primeira vez. Inicialmente desejamos boas vindas e, em seguida, resgatamos o primeiro encontro para aqueles que estavam ali pela primeira vez. Depois sentamos em círculo e perguntamos aos pais acerca do crescimento e desenvolvimento e sobre as atividades exercidas por eles no lar para a estimulação de seu filho, por meio das dinâmicas, apresentando seu filho e o boneco, respectivamente.

Neste momento do segundo encontro retomamos a segunda fase da Teoria Humanística de Paterson e Zderad, denominada o diálogo intuitivo, que envolve 0 encontro, o relacionamento, a presença e 0 chamado a uma resposta, desenvolvida com as famílias, quando utilizamos as observações dos cuidados realizados pelos pais com seus filhos.

Inicialmente, procurando estabelecer uma relação empática, despojando-nos de visões preconcebidas, conhecendo o outro intuitivamente. Nessa fase, o Tu se torna presente, a presença se instaura; 0 instante dá-se quando existe presença, encontro, relação(22). Nesse momento, utilizamos a dinâmica "com que cara está chegando", cuja finalidade era facilitar o entrosamento e conhecer a disposição dos participantes. Foi solicitado a cada participante construir um porta-retrato com moldura para desenhar a sua cara de chegada no grupo ${ }^{(23)}$.

Alegre, pois estou sempre de bem com a vida (Margarida).

Curiosa, porque eu sou assim (Girassol).

Sonolenta, porque pela manhã fico assim (Dália).

Estou alegre, logo estou com saúde graças a Deus e pra mim está sendo bom participar destes encontros (Lírio).

Alegre, porém um pouco apressada (Gardênia).

Por meio da dinâmica, cada pai pôde expressar sua disposição ao encontro, enfatizando a importância do grupo e incentivando os demais participantes mesmo diante de algum compromisso. Ao analisarmos estas falas, concordamos que cada um de nós é um ser singular e, por sermos todos diferentes, o tripé simpatia/empatia/antipatia ocorre de forma extraordinariamente pessoal, mas há em nós uma força interior capaz da enriquecer nossos relacionamentos ${ }^{(24)}$.

Na dinâmica "apresentando o seu filho", cada participante pôde demonstrar 0 aspecto do crescimento e desenvolvimento de seus filhos. Neste momento, dispomos, em um painel, as atividades realizadas pelo filho, como: anda, come, fala e "experencia" a vida. Cada participante retirou do painel e apresentou as ações executadas pelo seu filho.

Isso ele faz perfeito, anda sozinho (Lírio).

Vou escolher o come sozinho, pois foi a primeira coisa que ele aprendeu a fazer... (Margarida).

Meu filho come sozinho (Gardênia).
Fala perfeitamente, tudo (Girassol).

Ela faz tudo isso só, anda, fala, come e até mais, dança, lava louça... (Chuva de Prata).

Notamos que há certo orgulho por ver seu filho crescer e se desenvolver como as demais crianças, pois os portadores da síndrome de Down possuem um ritmo de desenvolvimento da linguagem lento.

Lírio, Margarida e Gardênia acreditam que seus filhos irão atingir sua expectativa, que é realizar suas atividades sozinhos, pois isso é só uma questão de tempo, porque eles estão se empenhando bastante para que isso aconteça.

A seqüência de desenvolvimento da criança com síndrome de Down geralmente é bastante semelhante à de crianças sem a síndrome, embora em um ritmo mais lento, conforme mencionado anteriormente. Esta demora em adquirir determinadas habilidades pode prejudicar as expectativas que a família e a sociedade têm da pessoa com síndrome de Down. Durante muito tempo estas pessoas foram privadas de experiências fundamentais para o seu desenvolvimento porque não acreditavam que fossem capazes. Todavia, atualmente, já é comprovado que crianças e jovens com síndrome de Down podem alcançar estágios muito avançados de raciocínio e de desenvolvimento ${ }^{(19)}$.

Direcionamos o diálogo para o terceiro objetivo do encontro: identificar as atividades executadas no lar para a estimulação de seu filho, mediante a dinâmica "o boneco"(25), em que, na forma de círculo e ao som de uma música, um boneco era entregue a um participante e 0 facilitador de costas para o grupo dava a oportunidade de passar 0 boneco para todos; porém, quando a música parasse, quem estivesse com o boneco deveria relatar as atividades exercidas no lar para a estimulação de seu filho.

Ponho-a para fazer as tarefinhas e acordo ela pra ir ao colégio (Dália).

Peço-Ihe para enxugar os talheres, colocar a toalha no varal, a sandália no quarto. Pretendo melhorar sua coordenação motora no próximo ano (Margarida).

Ensino ele a falar. Porque é a única coisa que eu quero. Mas também eu o coloco pra se vestir sozinho sempre dizendo como é o certo (Lírio).

Peço a ela para lavar suas peças íntimas e as louças do jantar (Girassol).

Diante dos depoimentos vimos que os pais estimulam seus filhos de várias formas, como na educação, na coordenação motora, na fala e nas responsabilidades com a higiene pessoal e doméstica. Para que isso aconteça é necessário que a família crie um ambiente favorável e estimulador e nunca falar por seu filho, devendo, também, observar suas características individuais e atender às necessidades específicas, ajudando-o a se comunicar e a ver a linguagem como uma forma facilitadora para a realização de seus desejos e expressão de seus sentimentos.

Atualmente, são realizados programas de estimulação precoce que visam a favorecer o desenvolvimento motor e intelectual das crianças com síndrome de Down. Estes programas indicam melhoras no desempenho da criança nos primeiros anos de vida. A estimulação precoce não é a cura da síndrome de Down, mas fornece oportunidades para o desenvolvimento dos potenciais da criança. É necessário, acima de tudo, que se acredite e se trabalhe com as potencialidades ${ }^{(3)}$.

A dinâmica ainda permitiu que os pais refletissem sobre o papel da família na condução do processo de desenvolvimento de seu filho no mundo social. A relação Eu-Tu ${ }^{(22)}$ permitiu-nos o conhecimento de cada 
participante/família, numa relação solidária, observando e utilizando meios de comunicação verbal e não verbal para captar os dados objetivos e subjetivos no cuidado.

No terceiro encontro buscou-se a fase do processo denominada diálogo cientifico, quando se estabelece a relação Eu-Isso(22). 0 conhecendo cientificamente 0 outro é o conhecimento vivenciado na relação sujeito-objeto, obtendo-se algum conhecimento pela coleta de dados, permitindo a interpretação, categorização e o acréscimo desse conhecimento $^{(7)}$.

Iniciamos, utilizando a dinâmica "o desejo ao próximo"(17). Cada participante, de posse de uma bexiga, colocava dentro uma mensagem de otimismo para alguém, então encheria o balão e quando todas as bexigas estivessem cheias cada um deveria manter ar numa representação de que esses desejos estariam se multiplicando para todos. No final, cada um pegou uma bexiga, estourou-a e leu a mensagem.

Quero que todos realizem seus desejos e que sejam felizes (Lírio).

Que o otimismo possa reinar em nossas vidas (Margarida).

O amor e a fé são muito importantes para a vida (Dália).

Força, garra e paz para enfrentar os obstáculos (Tulipa).

Nas falas dos participantes, evidenciamos vivências pessoais, familiares, fé e momentos felizes. Ficamos impressionadas com a liberdade que sentiram em expressar seus sentimentos, que revelaram felicidade, otimismo, força, amor, fé e paz como elementos importantíssimos para vivermos de bem com a vida e com o semelhante. O compartilhar do grupo deixa evidente a congruência do marco conceitual dessa metodologia, pois acreditamos que o ser humano se relaciona com os outros seres humanos, individualmente ou em grupos, e na sociedade como um todo ${ }^{(26)}$.

Ao analisarmos as mensagens dos depoentes Lírio, Margarida, Dália e Tulipa podemos até dizer que a felicidade depende de diversas variáveis, como a família unida, o envolvimento com a sociedade, ou seja, a prestação de ajuda do próximo e a intimidade com Deus, pois a fé é a base da coragem do $\operatorname{ser}^{(27)}$.

Para dar continuidade ao nosso encontro, utilizamos a dinâmica "cores dos sentimentos", que após a escolha de uma cor, seu sentimento seria expresso a partir dessa cor.

Branco, porque meu filho é sinônimo de paz, carinho... e Deus me deu ele assim para eu saber o que é amor de filho... (Tulipa).

Escolho o verde porque é a cor da esperança. E esse tempo todo que lutei por meu filho, apesar das dificuldades, teve muito sucesso, tenho esperança de coisas melhores para ele... (Margarida).

Rosa, porque simboliza ternura e é isso que minha filha transmite (Girassol).

Conviver com minha filha me traz muita paz. E que Deus dê muitos anos de vida e saúde para ela e o restante da família, por isso é que escolho o branco (Chuva de Prata).

Escolho o branco porque desejo muita paz e tudo que for bom pra ele. É aquilo que Deus me deu, é a minha missão (Gardênia).

Observamos que nestas falas as depoentes Tulipa, Chuva de Prata e Gardênia escolheram o branco porque representa a paz ao conviver com seus familiares e gostam muito de cuidar e do carinho de seus filhos, pois eles trazem uma força que proporciona o bem-estar da família. O portador da síndrome de Down é muito amoroso, comprovando esta afirmação na fala de Tulipa, em que ela expressa que só conhece 0 amor devido ao seu filho.

Os pais possuem esperança de dias melhores ou de que seus sonhos sejam realizados, como é o caso de Margarida, que almeja a independência e o ingresso de seu filho no mercado de trabalho. A ternura foi um dos sentimentos abordados entre os participantes, que para Girassol significa meiguice, carinho, amor e paz.

Podemos perceber sentimentos de paz, esperança, ternura e desejo divino, que os sentimentos são nosso sexto sentido, aquele que interpreta, organiza, dirige e resume os outros cinco $^{(28)}$. Os sentimentos nos dizem se o que estamos experimentando é alegre ou triste, prazeroso ou doloroso e ameaçador.

...posso até dizer mais amorosa que os outros filhos (Dália).

Minha linda tem 29 anos, há 10 anos estuda aqui, na APAE. Tem problemas na garganta por isso usa antibiótico. Ela comporta-se normal e é muito sensível. É uma coisa normal... (Girassol).

Ele tem 5 anos, há 2 anos estuda aqui. Já tomou fenobarbital e hoje só toma neuroleptil, em casa tem o comportamento hiperativo e não consegue se concentrar. Viver com uma criança com síndrome de Down é um desafio... (Gardênia).

Meu filho tem 12 anos, e há 9 anos estuda na APAE. Comporta-se bem e não toma remédio controlado. É uma pessoa normal, apenas precisa de mais atenção e carinho. Mas ele é um amor de pessoa, é muito atencioso comigo (Tulipa).

Diante dos depoimentos, vimos a responsabilidade e a preocupação dos pais em manter seus filhos na escola para que sejam estimulados e socializados também em ambiente fora do lar. Eles possuem uma vida normal, gostam de jogar bola, assistir à televisão, correr e brincar com os irmãos, mantendo, assim, um relacionamento familiar normal.

Analisando as respostas dos pais, percebemos que eles vivem normalmente, deixando transparecer que a família é a base para a integração de seus filhos, sem traumas na sociedade. Se o ambiente familiar não for incluso, com a criança participando de festas, indo aos mesmos locais dos irmãos, dos primos, a sociedade também não será(28).

A criança é um ser que pertence a um grupo familiar e necessita de amor e proteção para concretizar a sua existência. A família é saudável quando se constitui a partir de laços afetivos, expressos por gestos de carinho e amor, capazes de manifestar sentimentos, dividir conhecimentos, crenças e valores ${ }^{(6)}$. Os pais devem tratá-la como a seus outros filhos - com direitos, deveres e limites definidos. Na fase da adolescência, deve colocá-la em oficinas profissionalizantes mais coerentes com sua aptidão para que adquira maior independência familiar e financeira.

\section{CONSIDERAÇÕES FINAIS}

A proposta de utilizar dinâmicas para o desenvolvimento deste estudo teve a princípio o intuito de mostrar o quão é belo perceber o outro de forma humana e compreensiva, o olhar humanitário sobre os portadores de síndrome de Down e suas relações com a família, apoiadas pela Teoria Humanística, que mostra o encontro da família com o filho portador de síndrome de Down, retratando o seu conviver.

$\mathrm{Na}$ relação Eu-Tu, emergiram informações sobre os participantes, a caracterização de seus filhos, os aspectos do crescimento e desenvolvimento, a estimulação dos pais, o sentimento quanto às ações realizadas pelo filho no aspecto cognitivo-afetivo-social e motor. $\mathrm{Na}$ 
relação Eu-Isso, o que eles fazem para acompanhar o tratamento de seu filho e a compreensão acerca da doença. Na relação Nós, foi abordado o espírito de comunhão, ou seja, a verdadeira doação da família.

Assim, podemos relatar que a maioria dos pais entrevistados teve seus filhos antes dos 35 anos e só souberam que eles eram portadores da síndrome de Down após o nascimento dos mesmos. E ao receberem a notícia houve um momento de choque, mas logo aceitaram a idéia e abraçaram a causa de ter um filho especial, dando-lhes todo 0 amor que somente os pais são capazes de dar.

Observamos também que três dos sete participantes deste estudo têm certa dificuldade no cuidar de seus filhos no tocante à comunicação e um dos sete, na alimentação e convivência dele com outras crianças. Comprovamos também que alguns portadores da síndrome de Down realizam, com habilidade, o andar, o comer, o vestir e, além disso, eles dançam, executam as tarefas domésticas e têm facilidade de se comunicar. Isso se deve aos estímulos dados pela família e escola para que se tornem independentes, criando, assim, um ambiente propício para socialização e relacionamentos com diferentes pessoas.
Encontramos a paz, a esperança a ternura e o desejo divino nos depoimentos dos participantes quanto ao sentimento por seu filho, que traz a fé e a força na busca de dias melhores ou conquistas tão sonhadas. Percebemos que a família está sempre presente no cuidado, na educação, e em tudo que a criança precisar, seja de amor, de carinho, de compreensão, que eles estão ali dando todo o apoio e atenção. Observamos no estudo que a convivência familiar ocorre de forma natural, ou seja, os pais desempenham seu papel, dando uma atenção especial, tanto à educação, como ao amor, ao carinho, à fraternidade, enfim, dando-lhes uma boa base familiar, buscando sempre o estar melhor de seus filhos.

Os esforços dos pais que tentam diminuir as diferenças entre os portadores e os normais, como também diminuir e até combater o preconceito imposto pela sociedade foi bastante enfocado. Desenvolver este estudo para nós foi crescer como pessoa capaz de repensar 0 fazer e o ser e participar, juntamente com todos envolvidos, de uma nova maneira de oportunizar o crescimento da convivência, visando a favorecer o bem-estar e o estar melhor da família.

\section{REFERÊNCIAS}

1. Murahouschi J. Pediatria: diagnóstico mais tratamento. $6^{\text {a }}$ ed. São Paulo (SP): Sarvier; 2003.

2. Nettina SM. Prática de enfermagem. $6^{a}$ ed. Rio de Janeiro (RJ): Guanabara-Koogan; 1999.

3. Fundação Síndrome de Down. Síndrome de Down. [citado em: 29 set 2003]. Disponível em: URL: http://www.aleph.com.br/cdl/cdlZ.htm

4. Schwartzman JS. Síndrome de Down. São Paulo (SP): Mackenzie Memmon; 1999.

5. Dias HP. A responsabilidade pela saúde: aspectos jurídicos. Rio de Janeiro (RJ): Fiocruz; 1995.

6. Motta MGC. O ser docente no tríplice mundo da criança, família e hospital: uma descrição fenomenológica das mudanças existenciais [tese]. Florianópolis (SC): Universidade Federal de Santa Catarina; 1997.

7. Paterson JG, Zderad LT. Enfermeria humanistica. Cuidad de México (MEX): Limusa; 1979

8. Kleiman SJ. Paterson and Loretta Zderad: humanistic nursing theory with clinical applications. In: Parker ME. Nursing theories and nursing practice. Philadelphia (PA): F.A. Davis Company; 2001.

9. George JB. Teorias de enfermagem. Porto Alegre (RS): Artes Médicas; 2000

10. Costa EM, Castro DN, Pagliuca LMF Assistência de enfermagem: percepção da pessoa cega-reflexão sobre ética e solidariedade. Rev Bras Enferm 1999 out-dez; 52(4): 615-23.

11. Ministério da Saúde (BR). Agenda de compromisso para saúde integral da criança e redução da mortalidade infantil. Brasília (DF): MS; 2004.

12. Gil AC. Métodos e técnicas de pesquisa social. São Paulo (SP): Atlas; 1999.

13. Leopardi MT, Beck CLC, Nietzsche EA, Gonzales RMB. Metodologia da pesquisa na saúde. Santa Maria (RS): Palliot; 2001.

14. Brasil. Conselho Nacional de Saúde. Comissão Nacional de Ética em Pesquisa. Normas para pesquisas envolvendo seres humanos. Resolução No 196/96. Brasília (DF): CNS; 2000.
15. Bardin L. Análise de Conteúdo. Lisboa (POR): Edições 70; 1977.

16. Carraro TE, Randuz V. A empatia no relacionamento terapêutico: um instrumento de cuidado. Rev Cogitare Enfermagem 1996 jul-dez; 1(2): $50-2$.

17. Wall ML. Tecnologias educativas: subsídios para a assistência de enfermagem em grupos. Goiânia (GO): AB; 2001.

18. Thompson ED, Ashwill JW. Uma introdução à enfermagem pediátrica. $6^{\mathrm{a} e d .}$. Porto Alegre (RS): Artes Médicas; 1996.

19. Síndrome de Down. [citado em: 20 set 2004]. Disponível em: URL: http://www.aps.com.br/grupo

20. Rolim KMC. A enfermagem e o recém-nascido de risco: refletindo sobre a atenção humanizada [dissertação]. Fortaleza (CE): Universidade Federal do Ceará; 2003.

21. Associação Vitória Down. [citado em: 20 set 2004]. Disponível em: URL: http://www.vitoriadown.cjb.net

22. Buber M. Eu e Tu. Tradução de Newton Aquiles Von Zubem. $2^{\mathrm{a} e d .}$ São Paulo (SP): Moraes; 1974.

23. Caetano JA, Pagliuca LMF, Maciel MFA. A saúde-doença e a prática do autocuidado no olhar do portador do HIVIAIDS. RENE 2003 janjun; 4(1): 40-8.

24. Miranda S. Oficina de dinâmica de grupos. Campinas (SP): Papirus; 1999.

25. Militão A, Militão R. SOS dinâmica de grupo. $11^{\text {a }}$ ed. Rio de Janeiro (RJ): Qualitymark; 2005.

26. Carraro TE. Resgatando Florence Nightingale: a trajetória da enfermagem junto ao ser humano e sua família na prevenção de infecções [dissertação]. Florianópolis (SC): Universidade Federal de Santa Catarina; 1994.

27. Tillich P. A coragem de ser. $4^{\mathrm{a}}$ ed. Rio de Janeiro (RJ): Paz e Terra; 1991.

28. Bittencourt JFV. Compreendendo o pré-operatório de mastectomia aos olhos de quem vivencia [dissertação]. Belo Horizonte (MG): Universidade Federal de Minas Gerais; 2000.

29. Boff L. Principio de Compaixão e Cuidado. Petrópolis (SP): Vozes; 2000 . 